\title{
TENGO MIEDO TORERO, DE PEDRO LEMEBEL: \\ PASODOBLE E MELODRAMA
}

http://dx.doi.org/10.11606/issn.2237-1184.v0i29p141-149

Laura Janina Hosiasson

Universidade de São Paulo (USP)

\section{RESUM0}

Nos anos 80, Pedro Lemebel surgia no Chile como uma extravagância, como uma brincadeira licenciosa e imoral que se deixava abater sobre um meio social, cultural e politicamente estreitado. No espaço minado da ditadura, as performances, os programas de rádio e as crônicas foram as armas com as quais Lemebel exerceu sua política de resistência. Se no deboche dos espetáculos de Las Yeguas del Apocalipse (1987-1993), a denúncia do constrangimento político e sexual se propunha de uma maneira teatralizada, na escrita ela irá acolher uma diversidade de perspectivas pelas quais o problema se constrói no caminho de uma revisão histórica. Neste seu único romance, Tengo miedo torero (2001), a ditadura militar é penetrada pelo prisma do olhar periférico e marginal de um velho homossexual travesti. Lemebel convoca o expediente do cancioneiro musical do radinho de pilha da sua infância para combiná-lo acertadamente com o ritmo de melodrama. O resultado aponta para um binarismo antitético, preto no branco.

\section{RESUMEN}

Durante los años 80, Pedro Lemebel surgió en Chile como una extravagancia, una jugarreta licenciosa e inmoral que se dejaba caer sobre un medio social, cultural y políticamente estrecho. Dentro del espacio minado de la dictadura, las performances, los programas de radio y las crónicas fueron armas con las cuales Lemebel ejerció su política de resistencia. Si en los espectáculos de Las Yeguas del Apocalipsis (19871993) la denuncia de la represión política y sexual se proponía de manera teatralizada, en la escritura ella adoptará una pluralidad de perspectivas con las cuales el problema se construye en el camino de una revisión histórica. En esta su única novela, Tengo miedo torero (2001), la dictadura militar es penetrada a través del prisma de la mirada periférica y marginal de un homosexual travesti. Lemebel convoca el expediente del cancionero musical de su radio de pilas de la infancia y lo combina acertadamente con el ritmo del melodrama. El resultado apunta hacia un binarismo antitético, en contraste blanco y negro.

\section{PALAVRAS-CHAVE:}

Romance chileno; ditadura chilena; melodrama e literatura.

\section{PALABRAS-CLAVE:}

Novela chilena; dictadura chilena; melodrama y literatura. 


\author{
"Pensé que a mi obra le hacía falta una \\ potente historia de amor, y de esa forma \\ cruzo el zigzaguear de la loca con la \\ historia de la dictadura. Cruzo amor y \\ metralletas."
}

Pedro Lemebel

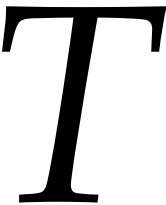
ditadura chilena, a esta altura já bastante volumosa. De fato, me parece possível arriscar com Grinor Rojo que toda a produção literária no Chile, a partir de 11 de setembro de 1973, estaria marcada de uma ou outra forma por esse acontecimento ${ }^{2}$. O que se observa, no entanto, é que na maioria dos casos não existe pretensão de abranger a totalidade do fenômeno do golpe militar de Pinochet, seus processos de instalação, perpetração e desinstalação. O que vemos comparecer são temas, sujeitos e perspectivas particulares, espaços, tempos ou destinos elaborados de maneira parcial, fragmentaria ou atomizada ${ }^{3}$.

Pedro Lemebel entrou nessa tradição para chacoalhar dentro dela uma série de pressupostos e entraves, como foi sempre seu modus operandi desde o começo, através de suas performances com o parceiro Francisco Casas ${ }^{4}$, depois em sua atividade como condutor de um programa de rádio ${ }^{5}$, para culminar com uma contundente atividade de cronista recolhida em vários livros e que ocuparia a maior parte de sua breve vida (1952-2015). O que me interessa aqui é verificar de que modo o sistema da "alta cultura" (outro dos seus alvos preferidos) recebe os dardos da escrita articulada neste seu único romance.

\footnotetext{
${ }^{1}$ LEMEBEL, Pedro. Tengo miedo torero. Barcelona: Seix barral, 2001.

2 ROJO, Grinor. Las novelas de la dictadura y la postdictadura chilena. ¿Qué y cómo leer? I e II. Santiago: LOM, 2016.

${ }^{3}$ LILLO, Mario. "La novela de la dictadura en Chile", Universidad de los Lagos: Revista Alpha, n. 29, 2009, pp. 41-54.

${ }^{4}$ A dupla se autodenominou Las Yeguas del Apocalipsis e suas aparições - entre 1987-1993 - em vernissages, lançamentos e outros eventos, eram absolutamente improvisadas.

${ }^{5}$ Entre 1994 e 2002, Lemebel conduziu um programa chamado Cancionero na rádio Tierra de Santiago, que combinava entrevistas, opiniões e seleções musicais de sua escolha pessoal.
} 
Apoiado num inventário musical de boleros, rancheras, couplets, $p a-$ sodobles e tangos e nutrido pela linguagem da cultura popular, o narrador elabora em ritmo cafona, amaneirado e excessivo, uma escrita em diálogo com uma tradição de escritores hispano-americanos irados e experimentais que flertaram também com essa "sensibilidade proscrita": entre eles, Lezama, Sarduy, Arenas, Puig, Perlongher. ${ }^{6}$

Em Lemebel, parece-me possível falar num tipo de radicalização desse recurso pela incorporação do movimento performático em seu interior. O próprio título do livro provém de um conhecido pasodoble espanhol, cujas estrofes serão cantaroladas em meio da trama. O tríptico 'tengo-miedo-torero' irá servir de senha secreta entre os protagonistas, abrindo-se para os lances de uma tauromaquia ao mesmo tempo desejada e temida. Digamos que a letra da canção paira sobre toda a história, à maneira de comentário em surdina. A narrativa espraia-se dessa forma, embalada por uma sequência um tanto aleatória de letras e melodias que o protagonista conhece de cor e irá salpicando parcimoniosamente, num ritmo de moto-contínuo e apontando para um saber que só ele domina e que, por isso mesmo, vale para ele como carta de trunfo. Mas essa pressuposição de superioridade no campo da imaginação contrasta com a impotência gerada pela impossibilidade de concretizar o desejo sempre adiado do encontro romântico e sexual. Por trás desses dois movimentos opera-se a consciência do passar do tempo: um tempo pleno da juventude e o tempo periclitante da entrada na velhice, no plano biográfico. No plano da história: o tempo da liberdade enfrentado ao da repressão do presente.

Essa combinação de opostos no plano das paixões do protagonista vem transcrita também no plano formal pelo contraponto entre $o$ expediente de cancioneiros melodramáticos e a transcrição de alguns anúncios da antológica Rádio Cooperativa (único meio de comunicação a dar voz à oposição durante os piores anos do regime militar) com notícias sobre prisões, desaparecimentos, revoltas violentamente abafadas, etc., o que assume ares de um "coro trágico". 7

O cancioneiro popular latino-americano e espanhol (essas "líricas pasadas de moda", "esos temas de ayer", "esa música alharaca") configura um universo de referências lacrimosas partilhado pelo protagonista e pelo leitor ideal. Ele funciona aqui em vários registros: como aparato intertextual de acesso a um saber enraizado no mais profundo da cultura popular hispano-falante, mas também como fonte de inspiração gay, termo que utilizo à revelia de Lemebel que preferia maricón e se encantou com o termo bicha quando ouviu a palavra em sua única visita ao Brasil, em 2013.

\footnotetext{
${ }^{6}$ MONSIVÁIS, Carlos. "Pedro Lemebel: el amargo, relamido y brillante frenesí", Prólogo a Lemebel, La esquina es mi corazón. (1995). $3^{\mathrm{a}}$ ed. Barcelona: Seix barral, 2004, pp. 9-19.

${ }^{7}$ BLANCO, Fernando. "Ciudad sitiada, ciudad sidada. Notas de lectura para Tengo miedo torero de Pedro Lemebel". Universidad Chile: Cyber Humanitatis, n. 20 (online), 2001.
} 
Esses dois registros matizam o prisma através do qual se observa o mundo. O procedimento será explicitado em chave irônica em vários momentos ao longo do livro, por exemplo quando la Loca8 devaneia com autocrítica sobre sua "lírica cebollera de amor barato, hemorragia de amor con tinta de sangre" que flui como "repicar de cataratas" em seu peito (p.38), ou quando apela ao "diálogo de comedia antigua...mirándolo con una llamarada de selva oscura" de que se vale para tentar comover seu jovem e distraído amado (p. 88). Ou ainda, em palavras do próprio Lemebel: "Para decirlo en lenguaje travesti, es como tener el ropero de la Lady Di en el computador". 9

Uma das características desse estilo se manifesta na anteposição reiterada do adjetivo ao substantivo, o que em certas situações sintáticas em espanhol produz um efeito rebuscado: "drástico mandato"; "blindado artefacto", "relajado comercio de tornasoleada vitalidade", "arácnido oficio de sus manos", "bullente diadema encantada del bolero"... Como apontamos acima, a linhagem mais óbvia dessa escrita "que se arriesga en el filo de la navaja entre el exceso gratuito y la cursilería y la genuina prosa poética y el exceso necesario" (MONSIVAIS, 2004), liga-o, entre outros, com Perlongher e os cubanos Sarduy, Arenas e Lezama Lima.

Acumulam-se hoje, por outro lado, os ensaios críticos 8101112 que apontam para a evidente filiação do protagonista de Tengo miedo torero com o travesti Manuel González Astica, alias la Manuela13, no romance Um lugar sem limites ${ }^{14}$, de José Donoso. Embora Lemebel nunca tenha feito alusão a esse evidente parentesco, várias de suas crônicas revisitam a figura do travesti, essa figura "con la alita rota", especialmente em Loco afán. Crónicas del sudário. ${ }^{15}$

Não resta a menor dúvida de que entre Donoso e Lemebel se abre uma distância sensível que não fala somente de tempos diversos na história do Chile, mas também de um escritor proveniente da rançosa aristocracia chilena e de outro, nascido numa favela. Donoso, o homossexual enrustido que nunca saiu do armário, e Lemebel, uma bicha escancarada. De um lado,

\footnotetext{
8 Ver: LÓPEZ MORALES, Berta. "La construcción de "la loca" en dos novelas chilenas: “El lugar sin límites" de José Donoso y "Tengo miedo torero" de Pedro Lemebel. Concepción: Revista Acta Literaria. (online) n. 42, 2011.

9 Apud MATEO DEL PINO, Ángeles, "Cronista y malabarista... (Entrevista a Pedro Lemebel)". Santiago: Cyber Humanitatis, n. 20, 2001 (134).

${ }^{10}$ BLANCO, Fernando. "Ciudad sitiada, ciudad sidada. Notas de lectura para Tengo miedo torero de Pedro Lemebel". Universidad Chile: Cyber Humanitatis, n. 20 (online), 2001.

${ }^{11}$ GUERRA CUNNINGHAM, Lucía. "Ciudad neoliberal y los devenires de la homosexualidad en las crónicas urbanas de Pedro Lemebel". Revista chilena de Literatura, n. 56, 2000, pp. 71-92.

${ }_{12}$ CANOVAS, Rodrigo. Sexualidad y cultura en la novela hispanoamericana. La alegoría del prostíbulo. Santiago: LOM, 2003.

${ }^{13}$ Ver CIFUENTES-JÁUREGUI, Ben. "El retorno de la Manuela: travestismo/identificación/lo abyecto en Loco afán, de Pedro Lemebel". Rutgers University: Inti. Revista de literatura hispánica, n. 69, 2009, pp. 171-85.

${ }^{14}$ DONOSO, José. El lugar sin límites. (1967). Barcelona: Seix barral, 1985.

${ }^{15}$ LEMEBEL, Pedro. Loco afán. Crónica del sidario. (1996). $2^{\mathrm{a}}$ ed. Santiago: LOM, 1997.
} 
o refinado letrado e professor de literatura inglesa; do outro, o rapaz criado ao som do rádio de pilha em frequência AM. Mas apesar dessas diferenças, os travestis 'la Manuela' e 'la Loca del Frente' parecem, de fato, saídos do mesmíssimo molde.

Aqui o homossexual velho e patético, em aposentadoria compulsiva, quase careca e com a dentadura postiça que nem sempre ele lembra de colocar, se assemelha também ao outro, no gosto pelos enfeites, as plumas, a dança e a paixão frustrada por um jovem heterossexual. Penso que é possível estabelecer mais uma linhagem direta, lembrando que em O lugar sem limite fulgura no centro da trama a performance da Manuela a dançar e rodopiar ao som de El relicario, um pasodoble da tauromaquia musical espanhola. Não somente ali e aqui tudo gira em volta de um travesti velho e desmilinguido. Os dois cancioneiros espanhóis evocados pela vitrola e pelo rádio de pilha funcionam em ambos os casos, como espelhos do embate entre uma sensibilidade pensada como feminina e a violência de um entorno reacionário e brutal, encarnado simbolicamente na tourada. Donoso elabora o impasse indo do patético ao trágico. A homofobia desempenha ali seu recalque brutal sobre o desejo. Mais de trinta anos depois, o descompasso que aqui também decorre do patético, resolve-se numa amizade e numa forma de carinho, sentimentos esses alimentados pela entrada do evento violento da ditadura militar e a vista desse inimigo comum.

Assim, munido do cancioneiro popular como forma, o romance transforma-se em melodrama. ${ }^{16}$ A "historia de amor mezclada con metralletas", embalada por sua "estética de brócoli mariflor" vem se enredar com o episódio histórico da malfadada tentativa de assassinato do general Augusto Pinochet em setembro 1986, no caminho entre Santiago e sua casa de campo em Cajón del Maipo, localidade a $40 \mathrm{~km}$ da capital. É justamente esse procedimento misturado da estrutura deste romance o que me interessa focar aqui.

O expediente do discurso indireto livre que faz confundir a voz do narrador com a sua, também lembra em muito a estratégia de Donoso, mas aqui o procedimento se mistura com outras formas de sedução. O deslizamento de registros vai se tornando imperceptível e o leitor fica capturado a meio caminho do espelho, sem saber mais se a imagem refletida é a do protagonista, a do narrador ou a própria...porque a leitura deste livro suga seu leitor para dentro dessa linguagem "autodenigrante" 17 , impelindo-o a

\footnotetext{
${ }^{16}$ Fernando Blanco já apontou para o expediente melodramático na escrita do romance em "Comunicación política y memoria en la escritura de Pedro Lemebel". In: Idem (ed.), Reinas del otro cielo. Modernidad y autoritarismo en la obra de Pedro Lemebel. Santiago: LOM, 2002, pp. 27-68. 17 MONSIVÁIS, Carlos. "Pedro Lemebel: el amargo, relamido y brillante frenesí", Prólogo a Lemebel, La esquina es mi corazón. (1995). $3^{\text {a }}$ ed. Barcelona: Seix barral, 2004, p. 17.
} 
olhar o mundo através do prisma de uma marginalidade entendida aqui no sentido do lugar à margem das ficções de centro, de equilíbrio e de norma, elaboradas pelo esquema burguês.

A pretensa ignorância de la Loca del Frente sobre o que está acontecendo em sua casa e sobre a verdadeira identidade do rapaz que invade esse espaço de um dia pro outro, se coaduna com a indeterminação do seu próprio nome: "Mejor no saber, mejor hacerse la lesa, la más tonta de las locas, la más bruta, que solo sabía bordar y cantar canciones viejas."18 No fingimento desse 'não saber' reside sua força, sua "treta del débil", tomando aqui de empréstimo a feliz expressão de Josefina Ludmer sobre as estratégias discursivas dos sujeitos historicamente silenciados. ${ }^{19}$ Porque é sem saber, embora no fundo sabendo perfeitamente do que se trata, que o idílio artificial se sustenta no esquema do melodrama. Sexo e violência beiram a todo momento o explícito antes de cair na cafonice completa neste livro híbrido, de difícil classificação.

A postura antiautoritária, está em Lemebel por toda parte, das performances dos anos oitenta (com o coletivo Las Yeguas del Apocalípsis) passando pela sua atuação como radialista em Radio Tierra (entre 1994 e 2002) até chegar nas crônicas em que as figuras retratadas são sempre facilmente classificáveis em dois campos muito bem definidos: fascistas "pinochetistas" (mesmo após o fim da ditadura) de um lado, e libertários do outro.

No romance ${ }^{20}$ há também uma separação sensível entre os homossexuais pró ditadura e os da resistência. O personagem Gonza, um estilista de gosto refinado que aconselha a mulher de Pinochet em matéria de vestuário e imagem, tem um referencial direto em Gonzalo Cáceres, maquiador chileno (hoje com 67 anos) que se especializou na preparação do rosto de figuras conhecidas em suas aparições televisivas, durante os anos da ditadura. Foi o maquiador de "todo mundo", autodenominado "apolítico". Por suas mãos passaram artistas, jornalistas, presidentes, entre os quais o mesmíssimo general Pinochet e sua mulher. Lemebel já havia pintado um ácido retrato dessa figura na crónica "Gonzalo (el rubor maquillado de la memoria)" ${ }^{21} \mathrm{Ou}$ seja, ser homossexual não é prerrogativa de nada em matéria ideológica, assim como também ser de esquerda não isenta a priori os preconceitos de gênero. Essa foi a ponta da faca de seu manifesto "Hablo por mi diferencia", proferido em 1986 para um público de resistência à ditadura pinochetista. Aí lançava à queima-roupa: “[...]

\footnotetext{
18 Idem, ibidem, p. 21.

${ }^{19}$ LUDMER, Josefina. "Las tretas del débil" em (org. Eliana Ortega). La sartén por el mango. San Juan de Puerto Rico: El Huracán, 1984.

${ }^{20}$ Lemebel morreu em 2015, antes de dar forma ao projeto de um segundo romance que já tinha esboçado.

${ }^{21}$ LEMEBEL, Pedro. Loco afán. Crónica del sidario. (1996). $2^{\mathrm{a}}$ ed. Santiago: LOM, 1997.
} 
porque la dictadura pasa/ $Y$ viene la democracia y detrasito el socialismo/ ¿Y entonces? ¿Qué harán con nosotros compañeros?/ ¿Nos amarrarán de las trenzas en fardos con destino a un sudario cubano?". 22 Também convém lembrar de outra declaração em entrevista de 199923 , na qual o intuito político de sua perspectiva fica evidente:

- ...el mundo homosexual es un universo enorme lleno de matices. Yo te podría hablar desde el mariconaje guerrero que yo practico nada más. No todas las homosexualidades tienen que ver con este discurso. Existe una homosexualidad gay, blanca, apolínea que se adosa al poder por conveniencia. En ese sentido hay minorías dentro de las minorías, lugares que son triplemente segregados como lo es el travestismo. No el travestismo del show que ocupa su lugar en el circo de las comunicaciones, sino que el travestismo prostibular. El que se juega en la calle, el que se juega al filo de la calle, ese es segregado dentro del mundo gay, o también son segregados los homosexuales más evidentes en este mundo masculino." 24

Não está demais reiterar que o lugar do homossexual escolhido como ponto de vista por Lemebel em toda sua obra desloca-se sempre para a periferia, para o lugar descentrado, fora do sistema, um espaço desestabilizador. Diante do horror da violência do Estado de Exceção, o olhar dessa perspectiva periférica imprime um ar de paródia em tom menor ao relato dos acontecimentos brutais e escabrosos, de maneira que o ritmo do melodrama vai se impondo, tendendo dessa forma a matizar a visão extremamente maniqueísta que ele próprio (o melodrama) paradoxalmente estabelece. ${ }^{25}$

O romance se estrutura na base da alternância de duas cenas que correm em paralelo: a da Loca sem nome, a quem só conhecemos pelo apelido que ela recebe dos vizinhos a sua volta ("La del Frente"), e a do general Pinochet, flagrado numa intimidade imaginada junto de sua mulher, Lucía Hiriart. A apresentação da história nesses dois planos expande-se também para uma percepção geral do espaço da cidade partida ao meio, culminando com um panorama social que escancara suas diferenças. Essa dinâmica, Lemebel traz de suas crônicas, nas quais a Santiago dos bairros altos e a dos bairros baixos são desenhadas geográfica e socialmente separadas por um abismo. Nessas crônicas, o corpo marginal e deslocado do homossexual circula em ambos os universos com uma liberdade que o diferencia das empregadas, choferes e demais trabalha-

\footnotetext{
${ }^{22}$ Idem, ibidem, p. 84.

${ }^{23}$ JEFTANOVIC, Andrea. El cronista de los márgenes. Entrevista a Pedro Lemebel. 1999. Disponível em: <http://www.letras.mysite.com/pl200608.html>.

${ }^{24}$ Apud JEFTANOVIC, Andrea. Op. cit.

${ }^{25}$ BROOKS, Peter. The melodramatic imagination: Balzac, Henry James and the mode of excess. New Haven and London: Yale University Press, 1976.
} 
dores, porque seu trânsito se dá através da relação sexual que altera as diferenças expostas nos demais intercâmbios de movimento de força de trabalho e de dinheiro. ${ }^{26}$

No romance, porém, o comércio do sexo está descartado já que o maricas é velho demais e está aposentado. Ele agora borda toalhas de mesa e lençóis para a burguesia, e canta...A relação com o universo da norma burguesa entra num esquema similar ao dos demais trabalhadores, a não ser pelo canto que encanta o rapaz estudante universitário, ele também em movimento de revolta e distanciamento. Nos caixotes que carrega para dentro da habitação de la Loca não há livros, há armas e munições.

É preciso dizer neste ponto que o pano de fundo, o falido atentado contra o general Augusto Pinochet, é somente isso: o cenário de fundo para esta pungente história de amor, fadada ao fracasso, assim como o atentado. A estrutura contrapontística aludida, em que os dois planos narrativos vão se alternando, padece de um evidente descompasso. Se a entrega da história do amor impossível de um homossexual velho e proletário com um estudante revolucionário de classe média nos seduz de início e vai se expandindo em complexidades e implicações, por outro lado, a narrativa da intimidade do ditador padece do tratamento enrijecido de uma caricatura patética, da qual não se consegue extrair verdade alguma.

Mas isso que detecto como o que poderia ser um descompasso da estrutura geral do romance vem se integrar de modo muito pertinente na proposta do melodrama pautado nas premissas do cancioneiro popular, adotado como estrutura de base e procedimento construtivo. Assim como no melodrama, o paradigma maniqueísta das letras desse cancioneiro antigo é elaborado a partir de opostos e contrários absolutos, levados ao paroxismo. A começar por Tengo miedo torero, que contrapõe o medo pela morte do toureiro à confiança absoluta em sua maestria e poder. A letra fala por si só:

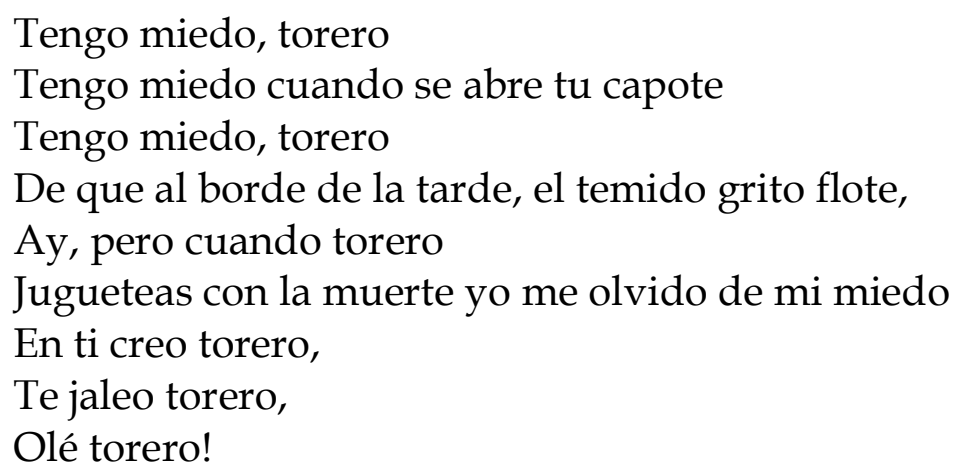

Quatro versos que repetem in crescendo o medo do/da amante diante do perigo que o toureiro corre na arena diante do touro; seguidos de quatro

${ }^{26}$ GUERRA CUNNINGHAM, Lucía. Op. cit. 
versos encabeçados pela adversativa 'pero' que levam ao 'Olé torero' final, enfrentando o medo com a confiança eufórica 'en ti creo torero'.

Movimento similar pode ser observado no restante do cancioneiro evocado no romance: Bésame Mucho opõe ao abraço e ao beijo, o afastamento e o desamor: "Piensa que talvez mañana yo ya estaré lejos, muy lejos de aqui". A tensão e intensidade se constroem no paroxismo dessas oposições. O mesmo acontece com o bolero El reloj ("Ella se irá para siempre cuando amanezca otra vez") e com Tú me acostumbraste ("Por eso me pregunto al ver que me olvidaste, por qué no me enseñaste cómo se vive sin ti"). Digamos que no universo amoroso da canção tradicional, mesmo quando a letra fala de encontro, como é o caso da balada chilena Aleluya, a paisagem tende a se bifurcar ("Es grande el mar/ más grande el cielo/ [...] Ojalá haya un lugar para los dos"). Lembrando aqui, com Roland Barthes27, como esses fragmentos nos levam a verificar a extrema solidão do discurso amoroso: "Desacreditada pela opinião moderna, a sentimentalidade do amor deve ser assumida pelo sujeito apaixonado como uma forte transgressão, que o deixa sozinho e exposto." 28

$\mathrm{O}$ romance de Pedro Lemebel situa-se em meio à vertigem da história chilena da ditadura militar numa tentativa de escancarar, feito preto no branco, as profundas cisões sociais que a sustentaram. Há nisso, em termos, um triunfo e um perigo de fraqueza. O triunfo está no despudor de uma fala periférica e na comovente desmistificação do eu que surge, a meu ver, como uma fala única em contexto latino-americano. Sua possível fraqueza residiria nas implicações um tanto simplistas desse binarismo de procedimento formal, preto no branco.

Laura Janina Hosiasson é livre-docente pela USP, onde leciona Literatura Hispano-americana. Autora do livro Nação e Imaginação na Guerra do Pacífico (2012), traduziu o peruano Julio Ramón Ribeyro (2007) e a chilena María Luisa Bombal (2013). Tem publicado numerosos capítulos em livros e artigos em revistas especializadas. Atualmente, prepara um livro sobre o escritor chileno, Alberto Blest Gana (1830-1920). Contato: lhosiass@uol.com.br

${ }^{27}$ BARTHES, Roland. Fragmento de um discurso amoroso (1977). Rio de Janeiro: Francisco Alves, 1981.

${ }^{28}$ Idem, ibidem, p. 157. 